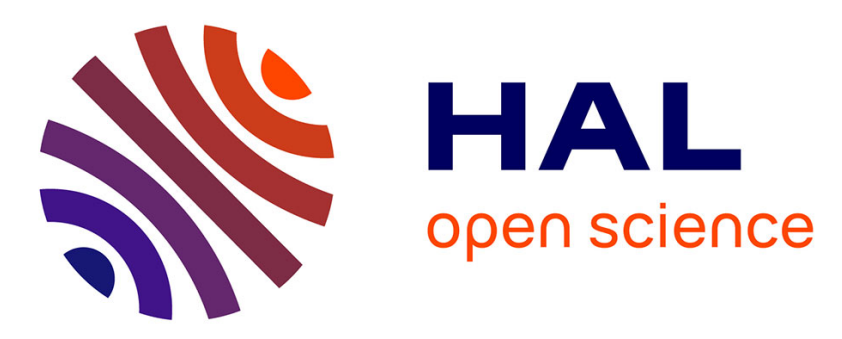

\title{
Two-Photon-Triggered NO Release via a Ruthenium-Nitrosyl Complex with a Star-Shaped Architecture
}

Margarita Romero Ávila, Andrés Felipe León-Rojas, Pascal G. Lacroix, Isabelle Malfant, Norberto Farfán, Rana Mhanna, Rosa Santillan, Gabriel Ramos-Ortiz, Jean-Pierre Malval

\section{To cite this version:}

Margarita Romero Ávila, Andrés Felipe León-Rojas, Pascal G. Lacroix, Isabelle Malfant, Norberto Farfán, et al.. Two-Photon-Triggered NO Release via a Ruthenium-Nitrosyl Complex with a Star-Shaped Architecture. Journal of Physical Chemistry Letters, 2020, 11 (16), pp.6487-6491. 10.1021/acs.jpclett.0c01953 . hal-02948930

\section{HAL Id: hal-02948930 \\ https://hal.science/hal-02948930}

Submitted on 4 Nov 2020

HAL is a multi-disciplinary open access archive for the deposit and dissemination of scientific research documents, whether they are published or not. The documents may come from teaching and research institutions in France or abroad, or from public or private research centers.
L'archive ouverte pluridisciplinaire HAL, est destinée au dépôt et à la diffusion de documents scientifiques de niveau recherche, publiés ou non, émanant des établissements d'enseignement et de recherche français ou étrangers, des laboratoires publics ou privés. 


\section{Two-Photon Triggered NO-Release Via a \\ Ruthenium-Nitrosyl Complex With a Star-Shaped}

\section{Architecture}

Margarita Romero Ávila, ${ }^{1,2}$ Andrés Felipe León-Rojas, ${ }^{2}$ Pascal G. Lacroix, ${ }^{* 1}$ Isabelle Malfant, ${ }^{1}$

Norberto Farfán, ${ }^{* 2}$ Rana Mhanna, ${ }^{3}$ Rosa Santillan, ${ }^{4}$ Gabriel Ramos-Ortiz, ${ }^{5}$ Jean-Pierre Malval $*^{3}$

${ }^{1}$ Laboratoire de Chimie de Coordination (LCC), CNRS, 205 route de Narbonne, BP44099,

Toulouse Cedex 4, 31077 France

${ }^{2}$ Facultad de Química, Departamento de Química Orgánica, Universidad Nacional Autónoma de México,04510 México D.F., México

${ }^{3}$ Institut de Science des Matériaux de Mulhouse CNRS-UMR 7361, Université de Haute Alsace, 15 rue Jean Starcky, 68057, Mulhouse, France.

${ }^{4}$ Departamento de Química, Centro de Investigación y de Estudios del IPN, CINVESTAV, Apdo., Postal 14-740, México, D.F., 07000, México.

${ }^{5}$ Centro de Investigaciones en Óptica, A.P. 1-948, 37000 León, Mexico

* E-Mails: pascal.lacroix@lcc-toulouse.fr, norberto.farfan@gmail.com, and jeanpierre.malval@uha.fr 
ABSTRACT. We report herein a molecular engineering strategy based on the design of a multipolar ruthenium-nitrosyl (Ru-NO) complex with a three-branched architecture. The three ruthenium-nitrosyl units are introducted at the periphery of a highly $\pi$-delocalized truxene core bearing three terpyridine ligands. The two-photon absorption capabilities of the complex were investigated by the Z-scan technics. The strong electronic coupling among the individual arms gives rise to a very strong two-absorption response $\left(\delta_{800 \mathrm{~nm}} \sim 1600 \mathrm{GM}\right)$, which corresponds to a 16 times enhancement of the capability of a single arm reference, promoting thereby an efficient light-driven NO release process in aqueous medium.

\section{TOC GRAPHICS}

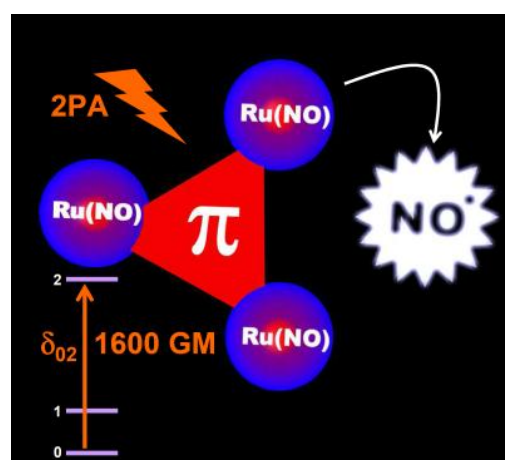

KEYWORDS Coordination Chemistry, Photo-activated Chemotherapy, Two-Photon Absorption, Z-scan, Nitric Oxide, NO delivery. 
With the advent of photo-activated chemotherapy, molecular engineering of light-activated nitric oxide (NO) donors ${ }^{1}$ has gained an increasing attention in regard to promising applications ${ }^{2}$ devoted to the spatio-temporal control of NO delivery in physiological environments. Indeed, regulating the concentration of this signaling molecule is of primary importance due to specific cellular responses to a local change of NO concentration. Various appealing biological effects of NO have been demonstrated. For instance, the successful action of NO against antibiotics resistance in biofilms in combination with methicillin has recently been reported. ${ }^{3}$ Additionally, the use of NO as anti-cancer agents ${ }^{4}$ has shown that the increase of NO concentration up to the $\mathrm{mM}$ range promoted both apoptosis and cells destruction. ${ }^{5,6}$ In this precise case, it is clear that targeting a malignant cell among a large population of healthy ones requires an efficient discriminating method to spatially localize and exterminate the growing tumor at sub- $\mu \mathrm{m}$ scale. Two-photon activation constitutes one of these appealing techniques. ${ }^{7,8}$ By tightly focusing a $f_{S-}$ pulse laser into the biomaterials, the resulting two-photon absorption (2PA) effect intrinsically confines the photoinduced process to a focal volume with feature size that perfectly fulfils such a spatial discrimination requirement. In addition, the near infrared wavelength light used for twophoton excitation allows a deep penetration into living tissues. In this context, various molecular design $^{\text {strategies }}{ }^{9-14}$ have been proposed to develop two-photon active chromophores incorporating a light-triggered NO releasable functionality.

Since the pioneer work of Wecksler et al. ${ }^{10}$ who demonstrated the feasibility of two-photon exciting a metal-nitrosyl complex associating an iron/sulfide/nitrosyl cluster and a moderate twophoton active fluorescein dye, various molecular design approaches have proposed alternative solutions which integrate more closely the metal-nitrosyl moiety into the 2PA conjugated subunit. ${ }^{11-13,15}$ By taking advantage of the strong electron withdrawing ability of the metal cation 
and its judicious positioning into a multibranched structure, very strong 2PA responses can be accounted. In line with this strategy, we present herein a multipolar ruthenium-nitrosyl (Ru-NO) complex (Scheme 1) which has been designed based on a three-branched truxene ligand (TX). This planar conjugated subunit ${ }^{16}$ was three-fold substituted with $2,2^{\prime}:$ 6',2"'-terpyridine anchoring groups positioned at the external rim of the truxene core. Each Ru-NO center is then coordinated by the three terpyridine nitrogens and also by an ancillary $2,2^{\prime}$ bipyridine ligand. Although most of the investigations were carried out in organic environment, it is noteworthy that such a single Ru-NO complex (i.e. $[\mathrm{Ru}(\mathrm{bpy})(\mathrm{tpy})-\mathrm{NO}]^{3+}$ ) has previously demonstrated its NO release ability upon light stimulation in aqueous medium. ${ }^{15,17,18}$ TX was synthesised by following modified procedures found in the literature, by coupling between a tris-boronated truxene and three iodoterpyridine. The nitrosyl ruthenium (RuTX) complex was prepared in four steps following reported methodologies. Details on the synthesis and complete characterisations of the complex are provided as supplementary materials.

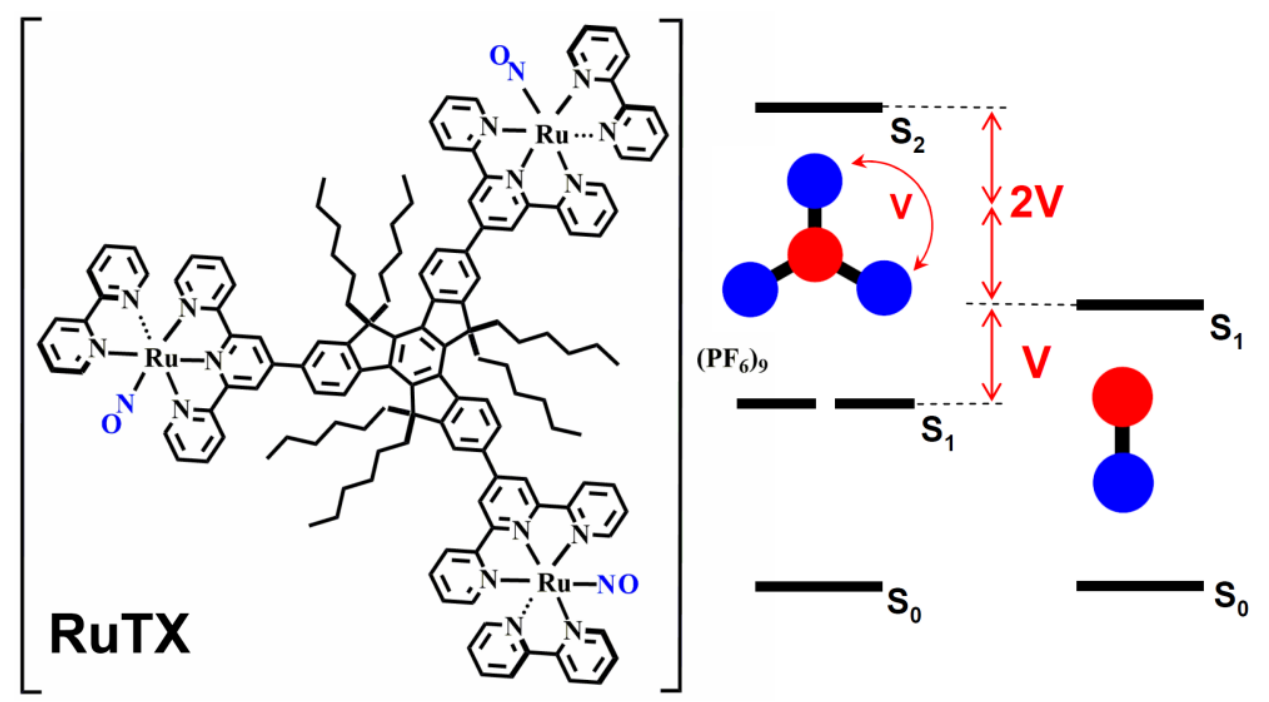

Scheme 1. (Left) Molecular structure of the Ru-NO complex (RuTX). (Right) Schematic representation of the effects of interbranch coupling on the electronic levels for a $\mathrm{C} 3$ three-branched symmetry. 
RuTX displays a star-shaped octupole retaining a $\mathrm{C}_{3}$ symmetry. In this multibranched architecture, the electronic coupling among the individual arms ${ }^{19,20}$ should lead to a synergy effect allowing very strong two-photon absorption responses with a concomitant light-triggered NO release ability.

Figure 1 shows the one- (1PA) and two-photon absorption (2PA) spectra of the Runitrosyl complex along with those of its truxene-based ligand (TX). The corresponding spectroscopic data are reported in Table S1.

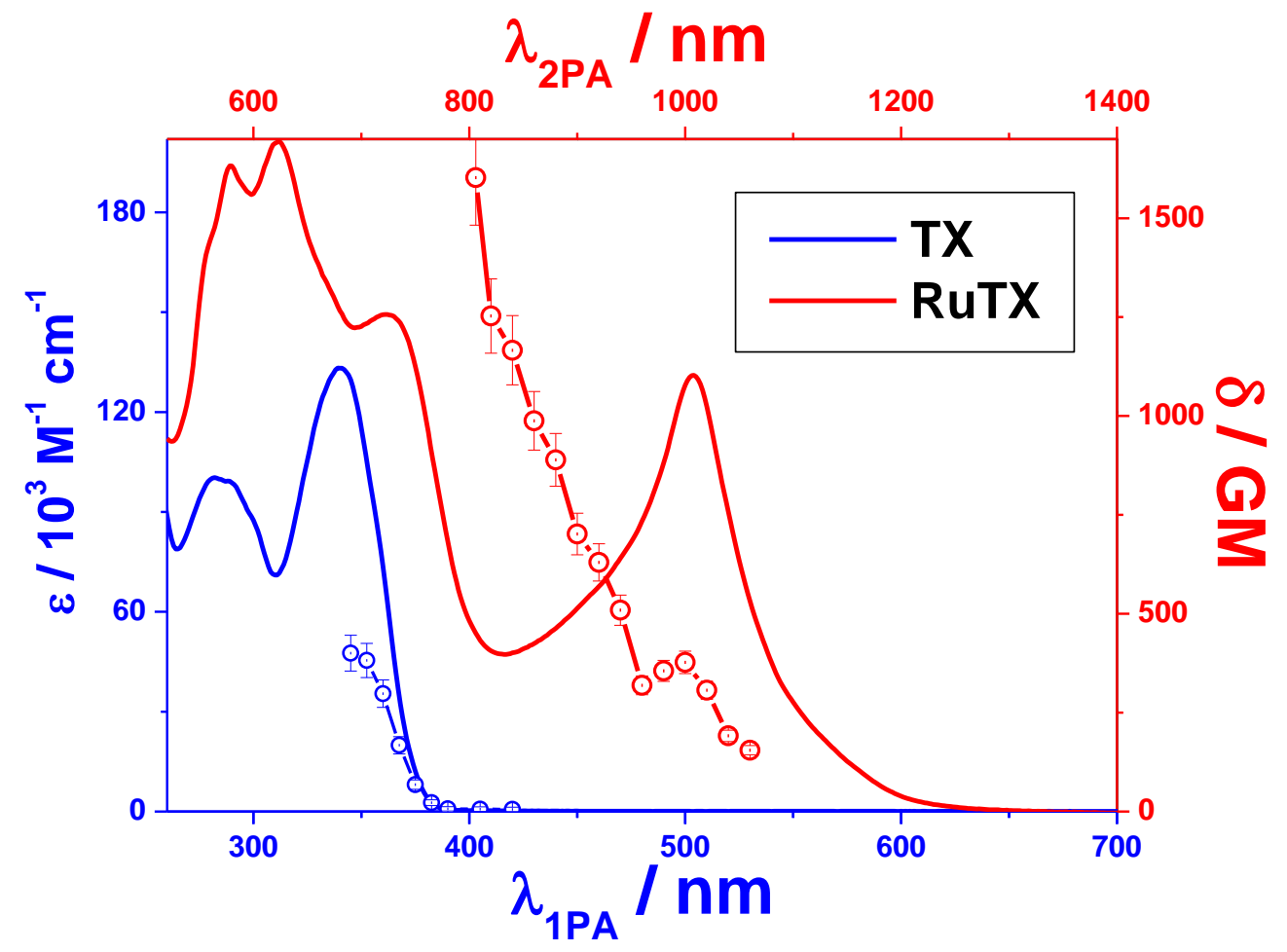

Figure 1. One- and two-photon absorption spectra of TX in dichloromethane (DCM) and RuTX in acetonitrile (ACN).

In the 260-400 $\mathrm{nm}$ range, the absorption spectrum of TX displays two distinctive bands: A structured band located at $282 \mathrm{~nm}$ and a very intense one $\left(\varepsilon_{\operatorname{MAX}} \sim 133000 \mathrm{M}^{-1} \mathrm{~cm}^{-1}\right)$ with $\lambda_{\mathrm{MAX}}=$ $340 \mathrm{~nm}$. The lower energy band should presumably correspond to strongly allowed $\pi-\pi^{*}$ 
transitions implying charge delocalization from the truxene core ${ }^{16}$ (donor) to the external terpyridine subunits (acceptors). Interestingly, on going from TX to RuTX, the introduction of strong electron withdrawing Ru-nitrosyl moieties clearly induces a very strong bathochromic shift of the longest wavelength band by about $9585 \mathrm{~cm}^{-1}(\sim 1.19 \mathrm{eV})$ which maintains a very strong absorption $\left(\varepsilon_{\mathrm{MAX}} \sim 132000 \mathrm{M}^{-1} \mathrm{~cm}^{-1}\right)$.

In parallel, the high-energy side of the absorption spectrum clearly displays two well-separated bands: a vibronically structured one at $311 \mathrm{~nm}$ which is typically observed upon metal-ligand bonding with terpyridine groups ${ }^{11,12}$ and a structureless band which is clearly emerging at 365 $\mathrm{nm}$. This latter band together with the lowest energy one are of particular interest since their occurrence directly results from the interplay and extent of electronic coupling between the three arms of the metal-complex. As illustrated in Scheme 1, RuTX can be regarded as an assembly of three-dipole like branches with identical $\mathrm{S}_{0}-\mathrm{S}_{1}$ energy if the interbranching coupling is negligible. However, if this latter interaction is strong (V in Scheme 1) the Frenkel ${ }^{20,21}$ exciton model predicts a splitting of the degenerate $S_{1}$ levels giving rise to a doubly degenerate $S_{1}$ state stabilized by an energy of $-\mathrm{V}$ and a third non-degenerated $\mathrm{S}_{2}$ state which becomes destabilized by an energy of $2 \mathrm{~V}$. According to this exciton coupling scheme, an estimated value of $\mathrm{V}$ can be obtained by measuring the $\mathrm{S}_{1}-\mathrm{S}_{2}$ energy gap on the absorption spectrum of RuTX (i.e. $\Delta \mathrm{E}_{12}=$ $3 \mathrm{~V})$. In this precise case, one should stress that for a pure $\mathrm{C}_{3}$-symmetry, the $\mathrm{S}_{0}-\mathrm{S}_{1}$ transition is one-photon allowed whereas the $\mathrm{S}_{0}-\mathrm{S}_{2}$ one is theoretically one-photon forbidden. However, the latter transition may become partially allowed upon relaxation to conformations with a lower symmetry. ${ }^{22,23}$ Therefore, the inter-arm interaction energy can be estimated to a value of $c a .0 .31$ $\mathrm{eV}$ for RuTX. Such a constant is comparable to that observed for $\operatorname{crystal} \operatorname{violet}^{19}(\mathrm{~V} \sim 0.37 \mathrm{eV})$ and denotes a strong interbranch cross-talk which can be oriented to enhance the 2PA response. 
Indeed, the case of the three-branched octupoles is very interesting since Beljonne et al. ${ }^{19}$ have previously predicted that the $2 \mathrm{PA}$ cross-section $(\delta)$ into the $\mathrm{S}_{2}$ excited state can be drastically amplified upon a judicious modulation of $\mathrm{V}$ with respect to the $\mathrm{S}_{1}$ state energy. In addition, such a rationalization has been experimentally confirmed for crystal violet, which exhibits a very high 2PA response into its $\mathrm{S}_{2}$ state with a $\delta_{\mathrm{MAX}}$ of about $2000 \mathrm{GM}$. If we consider now our Runitrosyl complex, one can expect a comparable 2PA amplification. The 2PA spectra of $\mathbf{T X}$ and RuTX are shown in Figure 1. According to our spectral resolution, both chromophores display a first resonance located respectively at $690 \mathrm{~nm}$ and $1000 \mathrm{~nm}$. These 2PA bands reasonably match their corresponding 1PA ones and display equivalent intensities with $\delta_{\mathrm{MAX}}$ in the $370-400 \mathrm{GM}$ range. But the most striking effect can be observed for RuTX which clearly undergoes an impressive 2PA enhancement in its high energy region $(<880 \mathrm{~nm})$ with $\delta$ of about $1600 \mathrm{GM}$ at $800 \mathrm{~nm}$. This very large 2PA cross-section can be readily attributed to the presence of the $\mathrm{S}_{0}-\mathrm{S}_{2}$ transition whose nonlinear absorption response nicely confirms the exciton model. ${ }^{19}$ Note that this $2 \mathrm{PA}$ enhancement can be even higher for $\lambda_{\mathrm{exc}}<800 \mathrm{~nm}$ but it cannot be quantified by our open-aperture z-scan method (see ESI) due to strong interferences of excited states absorption below $790 \mathrm{~nm}$. Therefore, it clearly appears that the photoinduced charge transfer process occurring from the truxene core to the peripherial Ru-nitrosyl subunits boosts the 2PA ability of RuTX but this primary process also constitutes a driving force promoting locally the Ru-NO bond dissociation. In order to exemplify this photodissociation reaction, the 1PA photolysis of RuTX has been first performed upon irradiation at $532 \mathrm{~nm}$ in acetonitrile. Figure 2A typically depicts the evolution of the absorption spectrum of RuTX during its visible irradiation. The longest wavelength absorption band undergoes a very slight blue shift associated to a subtle decrease of its intensity. In the $270-380 \mathrm{~nm}$ range, the photoinduced spectral changes are more 
significant. For instance, the structured band located at $290 \mathrm{~nm}$ which corresponds to terpyridinecentred transitions increases by a factor 1.25 . The presence of several isosbestic points also confirms the occurrence of an equilibrium reaction. To assess the formation of nitric oxides (NO) during the photolysis of RuTX, an ESR experiment was performed during this photoreaction in the presence of iron (II) $\mathrm{N}$-methyl-D-glucamine dithiocarbamato (Fe-MGD) used as a spin trap which generates a Fe-MGD-NO complex with a characteristic ESR signal. ${ }^{24}$ As shown in Figure 2B, the ESR spectrum of the mixture solution of RuTX/Fe-MGD after 20 min photolysis shows a triplet signal with a hyperfine splitting constant value of $\mathrm{a}_{\mathrm{N}}=1.2 \times 10^{-3} \mathrm{~cm}^{-1}$ and a g-factor of $\mathrm{g}=2.040$. This ESR signal is consistent with the formation of $\left[(\mathrm{MGD})_{2}-\mathrm{Fe}^{2+}-\mathrm{NO}\right]$ complex.
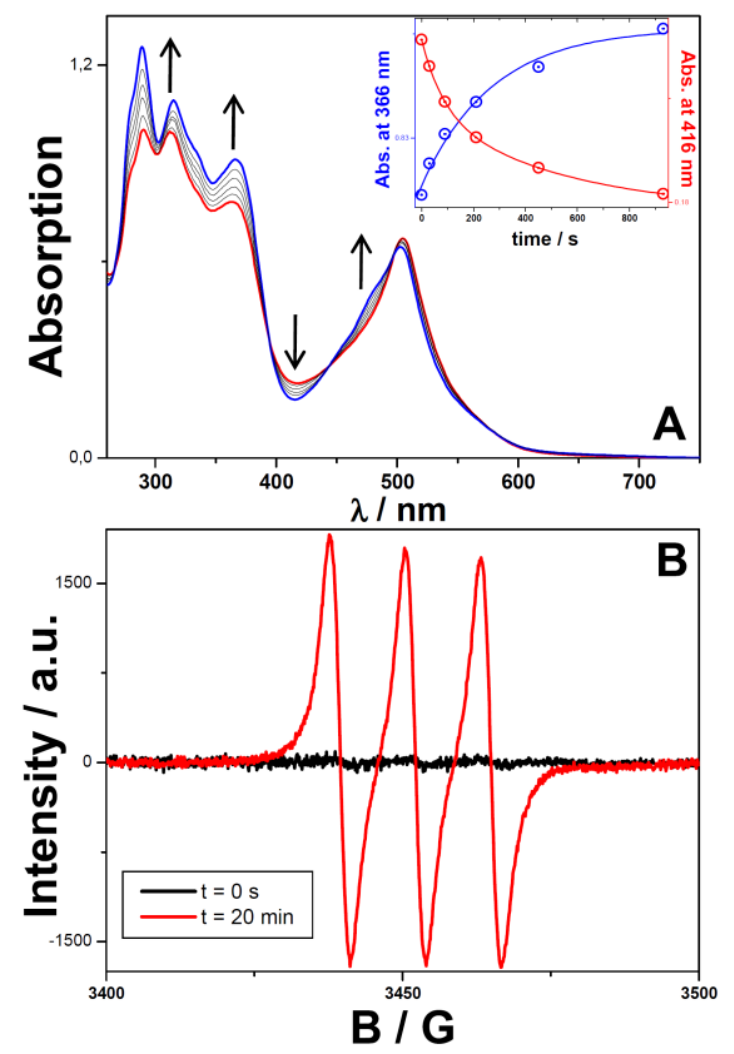

Figure 2. A. Evolution of the absorption spectrum of RuTX in solution of ACN upon irradiation at $532 \mathrm{~nm}$. (Inset : Time-dependent absorption changes at $366 \mathrm{~nm}$ and $416 \mathrm{~nm}$ ). B. Triplet ESR signals of RuTRX in presence of Fe-MGD before and after visible irradiation. 
It should be also underlined that if the same solution is kept initially in the dark, the presence of $\mathrm{NO}$ is not detected which confirms the photo-triggered character for the generation of NO. We next investigated this photorelease process upon two-photon excitation. For this purpose, two isomolar aqueous solutions of RuTX (c : $150 \mu \mathrm{M})$ mixed with Griess agent were irradiated respectively at $800 \mathrm{~nm}$ and $1000 \mathrm{~nm}$ using a $f s$-pulse laser whose average power was adjusted to the same value for both $\lambda_{\text {exc. }}$ Note that these two distinctive irradiation wavelengths were chosen since at these $\lambda_{\text {exc. }}$ the corresponding $2 \mathrm{PA}$ cross-sections of RuTX are significantly different with a $\delta$-ratio of about 4.2 between $800 \mathrm{~nm}$ and $1000 \mathrm{~nm}$. The progress of the photoreaction was monitored by recording the absorption spectrum of the solutions each 20 min irradiation (see Figure S3). The two-photon induced generation of NO is then revealed by its fast and quantitative reaction with the Griess agent yielding an 'azo' dye by-product which displays a large absorption band in the $450-600 \mathrm{~nm}$ range. ${ }^{11,12}$

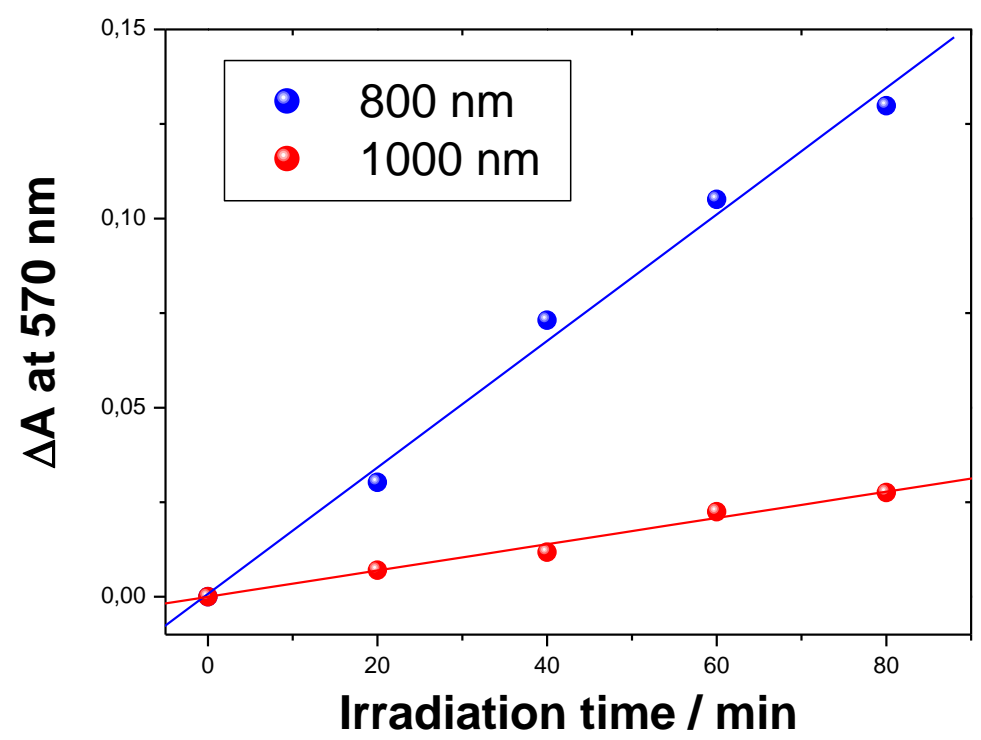

Figure 3. Kinetics of NO release upon two-photon excitation of RuTX at $800 \mathrm{~nm}$ and 1000 $\mathrm{nm}$ in presence of Griess reagent in aqueous medium $(\mathrm{H} 2 \mathrm{O} / \mathrm{ACN}: 1 \mathrm{v}: 1 \mathrm{v})$. The average incident power was maintained at $1.2 \mathrm{~W}$ for both $\lambda_{\text {exc }}$. 
Figure 3 typically shows the time-dependent increase of the absorbance at $570 \mathrm{~nm}$ for each RuTX solution distinctively irradiated at $800 \mathrm{~nm}$ and $1000 \mathrm{~nm}$. As shown in the Figure 3, the dynamic for the two-photon release of NO is clearly much faster for the irradiation at $800 \mathrm{~nm}$ than that observed for irradiation at $1000 \mathrm{~nm}$. It also appears that the generation of NO increases linearly with the NIR irradiation time suggesting a zero-order kinetics process. This timedependent effect was previously observed for other two-photon activable Ru-nitrosyl complexes $^{11}$ and, according to our experimental methodology, the slopes derived from these linear correlations should be directly connected to the two-photon uncaging cross-sections $\left(\delta_{u}\right)$. We have therefore estimated the $\delta_{\mathrm{u}}$-ratio between $800 \mathrm{~nm}$ and $1000 \mathrm{~nm}$ to a value of ca. 4.9. This ratio which nicely parallels that measured for the $2 \mathrm{PA}$ cross-sections (i.e. 4.2) suggests that the quantum yield for NO generation is globally invariant upon two-photon excitation in the 800$1000 \mathrm{~nm}$ range. It also confirms that the dynamic for two-photon release of NO can be significantly amplified when achieving the resonance into the highly two-photon activable $\mathrm{S}_{2}$ excited state of RuTX as predicted by the exciton model.

In summary, we have developed a new ruthenium-nitrosyl complex whose three-branched architecture allows a strong electronic coupling between each peripheral metal-center. Such an efficient interarm cross-talk in conjunction with the symmetry of the octupole clearly guarantee a synergy effect combining very strong $2 \mathrm{PA}$ cross-sections by three orders of magnitude in the NIR region with a light-driven release of nitric oxides in aqueous medium. 
ACKNOWLEDGMENT. The work has been performed within the framework of the FrenchMexican International Laboratory (LIA-LCMMC). Authors acknowledge support from PAPIIT (IN222819), PAIP and CONACYT and USAII for NMR spectra.

\section{ASSOCIATED CONTENT}

Supporting Information. The supporting information is available free of charge at...

1. Figures and Table: optical data (Table S1), optical spectra (Figures S1-S2). 2. Experimental procedures. 3. Synthesis and characterization of RuTX. 


\section{References}

(1) Rose, M. J.; Mascharak, P. K. Photoactive Ruthenium Nitrosyls: Effects of Light and Potential Application as NO Donors.Coord. Chem. Rev. 2008, 252, 2093-2114.

(2) Chen, G.; Roy, I.; Yang, C.; Prasad, P. N. Nanochemistry and Nanomedicine for Nanoparticle-based Diagnostics and Therapy. Chem. Rev. 2016, 116, 2826-2885.

(3) Bocé, M.; Tassé, M.; Mallet-Ladeira, S.; Pillet, F.; Da Silva, C.; Vicendo, P.; Lacroix, P.G.; Malfant, I.; Rols, M. -P. Effect of trans(NO, OH)-[RuFT(Cl)(OH)NO]( $\left.\mathrm{PF}_{6}\right)$ ruthenium nitrosyl complex on methicillin-resistant Staphylococcus epidermidis. Sci. Rep. 2019, 9, 4867, 1-8.

(4) Bonavida, B. Nitric Oxide (NO) and Cancer, Springer, New York, 2010.

(5) Xu, W.; Liu, L.Z.; Loizidou, M.; Ahmed, M.; Charles, I. G. The role of nitric oxide in cancer. Cell Res. 2002, 12, 311-320.

(6) Li, C. Q.; Wogan, G.N. Nitric oxide as a modulator of apoptosis. Cancer Lett. 2005, 226, $1-15$.

(7) Pawlicki, M.; Collins, H. A.; Denning R. G.; Anderson, H. L. Two - Photon Absorption and the Design of Two - Photon Dyes. Angew. Chem. Int. Ed. 2009, 48, 3244-3266.

(8) He, G. S.; Tan, L.-S.; Zheng, Q.; Prasad, P. N. Multiphoton Absorbing Materials: Molecular Designs, Characterizations, and Applications. Chem. Rev. 2008, 108, 12451330.

(9) Hishikawa, K.; Nakagawa, H.; Furuta, T.; Fukuhara, K.; Tsumoto, H.; Suzuki, T.; Miyata, N. Photoinduced Nitric Oxide Release from a Hindered Nitrobenzene Derivative by Two-Photon Excitation. J. Am. Chem. Soc. 2009, 131, 7488-7489.

(10) Wecksler, S. R.; Mikhailovsky, A.; Korystov, D.; Ford, P.C. Photosensitized NO Release from Water-Soluble Nanoparticle Assemblies. J. Am. Chem. Soc. 2006, 128, 3831-3837. 
(11) Akl, J.; Sasaki, I.; Lacroix, P.G.; Hugues, V.; Vicendo, P.; Bocé, M.; Mallet-Ladeira, S.; Blanchard-Desce, M.; Malfant, I. trans- and $\left.\underline{\text { cis- }}(\mathrm{Cl}, \mathrm{Cl})-\left[\mathrm{Ru}^{\mathrm{II}} \mathrm{FT}\right) \mathrm{Cl}_{2}(\mathrm{NO})\right]\left(\mathrm{PF}_{6}\right)$ : promising candidates for NO release in the NIR region. Photochem. Photobiol. Sci. 2016, $15,1484-1491$.

(12) Akl, J.; Sasaki, I.; Lacroix, P. G.; Malfant, I.; Mallet-Ladeira, S.; Vicendo, P.; Farfán, N.; Santillan, R. Comparative photo-release of nitric oxide from isomers of substituted terpyridinenitrosylruthenium(II) complexes: experimental and computational investigations. Dalton Trans. 2014, 43, 12721-12733.

(13) Enriquez-Cabrera, A.; Lacroix, P. G.; Sasaki, I.; Mallet-Ladeira, S.; Farfán, N.; BarbaBarba, R. M.; Ramos-Ortiz, G.; Malfant, I. Comparison of Carbazole and Fluorene Donating Effects on the Two - Photon Absorption and Nitric Oxide Photorelease Capabilities of a Ruthenium-Nitrosyl Complex. Eur. J. Inorg. Chem. 2018, 531-543.

(14) Wecksler, S.; Mikhailovsky, A.; Ford, P. C. Photochemical Production of Nitric Oxide via Two-Photon Excitation with NIR Light. J. Am. Chem. Soc. 2004, 126, 13566-13567.

(15) Enriquez-Cabrera, A.; Sasaki, I.; Bukhanko, V.; Tassé, M.; Mallet-Ladeira, S.; Lacroix, P. G.; Barba-Barba, R. M.; Ramos-Ortiz, G.; Farfán, N.; Voitenko, Z.; Malfant, I. Replacing Two Chlorido Ligands by a Bipyridine Ligand inRuthenium Nitrosyl Complexes with NO-Release Capabilities:A Comparative Study. Eur. J. Inorg. Chem. 2017, 1446-1456.

(16) Goubard, F.; Dumur, F. Truxene: a Promising Scaffold for Future Materials. RSC Adv. 2015, 5, 3521-3551.

(17) de Lima, R. G.; Sauaia, M. G.; Bonaventura, D.; Tedesco, A. C.; Bendhack, L. M.; da Silva, R. S. Influence of ancillary ligand $\mathrm{L}$ in the nitric oxide photorelease by the $[\mathrm{Ru}(\mathrm{L})(\mathrm{tpy}) \mathrm{NO}]^{3+}$ complex and its vasodilator activity based on visible light irradiation. Inorg. Chim. Acta 2006, 359, 2543-2549. 
(18) Labra-Vázquez, P.; Bocé, M.; Tassé, M.; Mallet-Ladeira, S.; Lacroix, P. G.; Farfán, N.; Malfant, I. Chemical and photochemical behavior of ruthenium nitrosyl complexes with terpyridine ligands in aqueous media. Dalton Trans. 2020, 49, 3138-3154.

(19) Beljonne, D.; Wenseleers, W.; Zojer, E.; Shuai, Z.; Vogel, H.; Pond, S. J. K.; Perry, J. W.; Marder, S. R.; Brédas, J. L. Role of the Dimensionality on the Two-Photon Absorption Response of Conjugated Molecules: The case of Octupolar Compounds. Adv. Funct. Mater. 2002, 12, 631-641.

(20) Terenziani, F.; Katan, C.; Badaeva, E.; Tretiak, S.; Blanchard-Desce, M. Enhanced twophoton absorption of organic chromophores: theoretical and experimental assessments. Adv. Mater. 2008, 20, 4641-4678.

(21) Davidov, A. S. Theory of molecular excitons, Plenum Press, New York, 1971.

(22) Latouche, C.; Akdas-Kilig, H.; Malval, J.-P.; Fillaut, J.-L.; Boucekkine, A.; Barone, V. Theoretical evidence of metal-induced structural distortions in a series of bipyrimidinebased ligands. Dalton Trans. 2015, 44, 506-510.

(23) Savel, P.; Akdas-Kilig, H.; Malval, J.-P.; Spangenberg, A.; Roisnel, T.; Fillaut, J.-L. Metal-induced dimensionality tuning in a series of bipyrimidine-based ligands: a tool to enhance two-photon absorption. J. Mater. Chem. C 2014, 2, 295-305.

(24) Liu, J.; Duan, Q.; Wang, J.; Song, Z.; Qiao, X.; Wanga, H. Photocontrolled nitric oxide release from two nitrosylruthenium isomer complexes and their potential biomedical applications. J. Biomed. Opt. 2015, 20, 1-7. 